\title{
Landscape biogeography and population structuring of a facultatively amphidromous galaxiid fish, Galaxias brevipinnis
}

\author{
Jason Augspurger ${ }^{1}$, Matt Jarvis ${ }^{1}$, Graham Wallis ${ }^{1}$, Tania King ${ }^{1}$, Travis Ingram ${ }^{2}$, Andy \\ Hicks $^{3}$, and Gerard Closs ${ }^{1}$ \\ ${ }^{1}$ University of Otago \\ ${ }^{2}$ University of Otago Department of Zoology \\ ${ }^{3}$ Hawke's Bay Regional Council
}

June 4, 2021

\begin{abstract}
Processes responsible for population structuring across spatial and temporal scales represent key components in understanding speciation and evolution. We use a hierarchical approach to investigate the degree and mechanisms of structuring in landlocked and diadromous populations of the facultatively amphidromous fish Galaxias brevipinnis across various temporal and spatial scales in southern New Zealand. To determine long-term structuring, multiple lakes and coastal sites were compared genetically. Short-term structuring was assessed using otolith microchemistry for a subset of sites, and behavioural mechanisms driving population structuring were assessed via larval distributions. Genetic data show that lakes foster divergence of lake-developing populations from each other and from coastal stream populations, whereas there is relatively little structuring within coast or lake populations. However, otolith analyses indicate that on a shorter time scale, most larvae do not disperse, i.e. recruitment is local. Thus, lake and coastal populations show a distinct meta-population structure based on catchment, in contrast to the prevailing assumption of widespread dispersal, with implications for management. Most larvae were distributed in river plumes, suggesting that a simple larval behavioural mechanism, e.g. positive rheotaxis, may result in larval retention within catchments and lakes. However, not all larvae were retained in plumes, creating opportunities for genetic exchange within-lake or among coastal sites. Genetic divergence of lake populations as a consequence of landscape and behaviour provides an insight into the potential of G. brevipinnis to diversify and speciate, when landscape and circumstances align, and also has implications for the management of this and other facultatively amphidromous species.
\end{abstract}

Landscape biogeography and population structuring of a facultatively amphidromous galaxiid fish, Galaxias brevipinnis

Jason M. Augspurger ${ }^{1,2}$, Matt G. Jarvis ${ }^{1}$, Graham P. Wallis ${ }^{1}$, Tania M. King ${ }^{1}$, Travis Ingram¹ , Andy S. Hicks ${ }^{3}$ and Gerard P. Closs ${ }^{1}$

${ }^{1}$ Department of Zoology, University of Otago, Dunedin, New Zealand

${ }^{2}$ Current affiliation: Otago Regional Council, Dunedin, New Zealand

${ }^{3}$ Hawke's Bay Regional Council, Napier, New Zealand

*Corresponding author: Jason.augspurger@orc.govt.nz

\section{Abstract}

Processes responsible for population structuring across spatial and temporal scales represent key components in understanding speciation and evolution. We use a hierarchical approach to investigate the degree and mechanisms of structuring in landlocked and diadromous populations of the facultatively amphidromous 
fish Galaxias brevipinnis across various temporal and spatial scales in southern New Zealand. To determine long-term structuring, multiple lakes and coastal sites were compared genetically. Short-term structuring was assessed using otolith microchemistry for a subset of sites, and behavioural mechanisms driving population structuring were assessed via larval distributions. Genetic data show that lakes foster divergence of lakedeveloping populations from each other and from coastal stream populations, whereas there is relatively little structuring within coast or lake populations. However, otolith analyses indicate that on a shorter time scale, most larvae do not disperse, i.e. recruitment is local. Thus, lake and coastal populations show a distinct meta-population structure based on catchment, in contrast to the prevailing assumption of widespread dispersal, with implications for management. Most larvae were distributed in river plumes, suggesting that a simple larval behavioural mechanism, e.g. positive rheotaxis, may result in larval retention within catchments and lakes. However, not all larvae were retained in plumes, creating opportunities for genetic exchange within-lake or among coastal sites. Genetic divergence of lake populations as a consequence of landscape and behaviour provides an insight into the potential of $G$. brevipinnis to diversify and speciate, when landscape and circumstances align, and also has implications for the management of this and other facultatively amphidromous species.

KEYWORDS : diadromy, gene flow, genetic structure, population dynamics, population genetics, speciation

\section{Introduction}

Processes responsible for population structuring are key to understanding population dynamics and speciation. Isolation occurs on a continuum from longer, multi-generational timescales, whereby populations genetically diverge through selection and genetic drift, to much shorter timescales (even a single generation), when immigration is rare enough to produce distinct ecologically closed (i.e. self-recruiting) populations, that may still maintain genetic connectivity over the long term (Dunning, Danielson, \& Pulliam, 1992; Kekkonen et al., 2011; Slobodkin, 1980; Jones et al., 2009). Furthermore, genetic shifts may occur through strong selection acting over relatively short timescales (Carroll, Hendry, Reznick, \& Fox, 2007; Fussmann, Loreau, \& Abrams, 2007), despite populations maintaining some genetic connectivity (Moody et al., 2015). As a result, it is often difficult to determine the degree and timescale at which population connectivity occurs (Fussmann et al., 2007; Levin, 1992). Therefore, evaluating both short- and longer-term population structuring is key in determining both ecological and evolutionary dynamics. To determine why population structuring occurs and differs on various spatial and temporal scales, the mechanisms driving population structuring must also be examined (Levin, 1992).

Behaviour and life history traits can interact with landscape and generate context-dependent patterns of isolation, and therefore population structure, across various temporal scales. Dispersive or migratory behaviours (Cowen, Lwiza, Sponaugle, Paris, \& Olson, 2000; Dingle \& Drake, 2007) tend to maintain open populations, where individuals are often exchanged. (Pinsky et al., 2017). If migratory pathways fragment and behavioural mechanisms favour local retention as opposed to connectivity, isolation may occur causing open populations to become closed (self-recruiting) (Booth, Montgomery, \& Prodöhl, 2009; Hughes, Schmidt, Macdonald, Huey, \& Crook, 2014). Understanding behavioural mechanisms is essential in instances where structured populations form despite no apparent barriers to genetic exchange or structuring mechanisms (Levin, 1992).

Amphidromous fishes provide an ideal system to investigate behavioural mechanisms leading to open and closed population structuring across timescales due to the combination of stream resident adults and a potentially dispersive marine pelagic larval phase (Augspurger, Warburton, \& Closs, 2017; McDowall, 2007). Amphidromous fishes spawn in freshwater. After hatching, larvae drift downstream to a marine pelagic environment, develop for a period of typically 3-6 months, then return to freshwater fluvial environments as juveniles where they remain for life. Many such species are thought to disperse during the larval phase and maintain open populations across broad geographic distributions (McDowall, 2003, 2007). In contrast, other species appear to resist dispersal, resulting in relatively closed populations across short (Hogan, Blum, Gilliam, Bickford, \& McIntyre, 2014; Sorensen \& Hobson, 2005; Warburton, Jarvis, \& Closs, 2018) and even 
long timescales (Hughes et al., 2014) despite no obvious barriers preventing connectivity.

Amphidromous fishes also often form landlocked populations, the life-history of which is nearly identical to their diadromous counterparts, with fluvial juvenile and adult forms and pelagic larvae. In this case, however, larval development occurs in a lake rather than the marine environment (Augspurger et al., 2017). This landlocking provides further potential for closed and open population structuring across timescales, as lakes can provide an opportunity for the isolation and genetic divergence of populations (Gouskov \& Vorburger, 2016; King, Young, Waters, \& Wallis, 2003). Closed landlocked populations diverge further genetically, subsequently radiating into non-migratory forms and species complexes (Allibone \& Wallis, 1993; Allibone et al., 1996; Burridge, McDowall, Craw, Wilson, \& Waters, 2012; Goto, Yokoyama, \& Sideleva, 2015; Yamasaki, Nishida, Suzuki, Mukai, \& Watanabe, 2015). In other cases, landlocked populations maintain connectivity with diadromous populations across longer-term timescales (Goto \& Arai, 2003; Hicks et al., 2017). Behavioural mechanisms during the larval pelagic phase, such as orienting into current, may play a role in determining connectivity across both short- and long timescales.

Galaxias brevipinnis is a facultatively amphidromous fish distributed throughout New Zealand, with great capacity for forming both diadromous and landlocked populations (McDowall, 1990). Landlocked populations of $G$. brevipinnis are potentially isolated from diadromous populations as their larvae develop in lakes, but do not appear to drift downstream out of them (Hicks et al., 2017). This may be due to their strong rheotactic behaviour after hatching, which may limit dispersal from their pelagic developing environment (Hicks, 2012). Further, diadromous adults are rarely found upstream of lakes, despite the absence of any obvious in-stream barriers blocking access, possibly due to the lack of a rheotactic cue allowing juveniles to navigate through large pelagic environments (Hicks, 2012; Jarvis \& Closs, 2019). Thus, populations of G. brevipinnis may potentially exhibit context-dependent degrees of population isolation and genetic structuring, creating an ideal opportunity to examine the importance and interaction of behaviour and landscape on population connectivity across temporal and spatial scales.

Here we investigate patterns of hierarchical population structuring in G. brevipinnis across spatial and temporal scales, and the possible role of behaviour in generating population structuring. We use genetic analyses to determine population structure across long multi-generational timescales, analysis of otolith trace element signatures to evaluate population structure over short timescales (the processes sustaining a population over a single generation), and larval trawling to determine larval distribution as a result of behaviour. We hypothesized that population structuring would interact with landscape, and generated a number of hypotheses in this context. Over long timescales, we predicted that: (1) coastal populations would tend to show high genetic homogeneity, indicating open populations like those of other amphidromous fishes, while (2) landlocked populations would show closed populations and some genetic divergence from other landlocked populations and coastal sites. Over short timescales, we hypothesized that: (3) landlocked and coastal stream populations would develop within their respective systems (e.g. lake or ocean), and (4) otolith trace element signatures would reflect catchment level meta-populations within lakes and along coastlines, forming semi-closed (selfrecruiting) populations on short-term timescales that are isolated to varying degrees despite some level of genetic exchange across longer-timescales. Finally, we hypothesized that: if otolith clustering occurred, (5) larval distribution would show higher larval densities in river plumes.

\section{Methods}

\section{Study sites, sampling design and method selection}

To address population structuring on both short and long timescales, as well as underlying behavioural causes, a variety of methods and hierarchical spatial scales of sampling were used. We used genetic methods to assess patterns generated over long term timescales, and otolith microchemistry and behaviour (larval distribution) to assess patterns generated over short timescales.

\section{Site selection for population genetics (hypotheses 1, 2)}

Genetic structuring was evaluated within and among lake tributaries, and among coastal stream populations. 
Pairwise comparisons among lake tributary populations, and between lake tributary and coastal stream populations were expected to show the highest levels of structuring. Coastal streams, and catchments with lakes were selected along an approximately 450-km north-south range of New Zealand's West Coast (total eight lakes and 16 coastal sites, Fig. 1). Six lakes in four West Coast river catchments (Buller River - Lakes Rotoiti, Matiri, Rotoroa; Grey River - Lake Christabel; Paringa River - Lake Paringa; Moeraki River - Lake Moeraki) were selected based on varying proximity to the coast, ranging from only a few kilometers for Paringa and Moeraki to a substantial distance inland for the others $(>80 \mathrm{~km})$. To help determine the cause of structuring, lake tributaries were paired with coastal streams downstream of the lake in the same river catchment as close as possible to the lake outlet as well as open coastal sites located in different catchments lacking lakes ( $n=16$ coastal sites total [8 downstream of lakes, 8 open coast]; Fig. 1 ).

To add a further level of potential isolation, two lakes draining to the east coast of New Zealand were included (Lakes Wanaka and Wakatipu). Both lakes are located approximately $300 \mathrm{~km}$ from the coast and upstream of two large hydroelectric dams (both $<80$ years old) creating impermeable barriers to migration from coastal populations. There is, however, no barrier to migration between Lakes Wanaka and Wakatipu. Potential within-lake structuring was assessed in Wanaka and Wakatipu because of their large size (lake area $>170 \mathrm{~km}^{2}$; max depth $>300 \mathrm{~m}$ ) and multiple spatially isolated inflowing tributaries. To conduct within-lake comparisons, five tributaries spanning the length of both lakes were selected and also used to test connectivity across shorter timescales using otolith analyses (Fig. 1).

\section{Genetic techniques and analyses}

Up to 30 adult fish were captured at each coastal stream and lake tributary site via backpack electric fishing, anesthetized, and a portion of the caudal fin removed and preserved in 100\% ethanol. Genomic DNA was isolated from fin clips following a modification of Casquet, Thebaud, and Gillespie (2012), using $300 \mu \mathrm{l} 5 \%$ chelex 100 (Bio-Rad) in $1.5 \mathrm{ml}$ tubes, $40 \mu \mathrm{g}$ Proteinase $\mathrm{K}$, and a final $90^{\circ} \mathrm{C}$ heating step for 10 min. Microsatellite genotyping was performed using 10 primer sets developed for Galaxias brevipinnis (Genbank Accession \#MK783109-MK783118) and two loci developed for G. vulgaris(Waters, Esa, \& Wallis, 1999) that cross-amplify G. brevipinnis . These 12 loci were genotyped using two methods: (1) 8-9\% nondenaturing acrylamide gels stained with SYBR Green 1 (ThermoFisher) scored manually against a 10-bp ladder (ThermoFisher) and (2) in multiplex groups ( Gbr 02, Gbr 10, Gbr 16 labelled with 6-FAM; Gvu 05, Gvu 07, Gbr 12 with VIC; Gbr 09,Gbr 13 Gbr 22 with NED; Gbr 07, Gbr 14 and Gbr 21 with PET) following Schuelke (2000) with modifications described in Townsend, King, and Jamieson (2012). Genotypes were scored using GeneMapper V4.1 (ThermoFisher).

Genetic diversity estimates $H_{\mathrm{o}}, H_{\mathrm{e}}, N_{e}$ and $F$ IS were calculated for each sampled population using the GenAlEx excel add on (Peakall \& Smouse, 2006). To test for Hardy-Weinberg equilibrium, a Fisher's Exact test using GenePop (Rousset, 2008; Raymond \& Rousset, 1995) was carried out with the default settings and Bonferroni corrections were applied (Sham \& Purcell, 2014). Population genetic structuring was determined by pairwise $F$ ST calculated in the GenAlEx excel add on (Peakall \& Smouse, 2006). To evaluate potential isolation by distance, pairwise $F$ ST was compared to pairwise geographic distance, measured by water way connection for each category of pairwise comparison (e.g. lake tributary-lake tributary, lake tributary-coastal stream, coastal stream-coastal stream). Significance of the distance patterns was determined using the Mantel test in GenAlEx where possible. Interpretation of genetic results was aided by Bayesian clustering data from the program STRUCTURE 2.3 (Pritchard, Stephens, \&Donnelly, 2000). Twenty replicates of a model with a burn in period of 20,000 iterations and run time of 30,000 iterations were run for all numbers of populations $K$ from 1-24. The CLUMPAK online service was used to aggregate STRUCTURE runs and determine the most probable number of populations (Kopelman et al., 2015).

\section{Site selection for otoliths (hypotheses 3,4 )}

To determine short-term population structure, and allow comparisons with genetic results, within-lake and coast patterns were evaluated by examining otolith trace element signatures from juveniles returning to streams sampled from a subset of sites used in the genetics study. Otolith trace element signatures provide 
a measure of potential mixing or separation of populations from a given tributary (Campana, 1999). As returning juveniles are all from the same cohort, and otolith trace element signatures are influenced by a large number of factors (Elsdon \& Gillanders, 2005; Grammer et al., 2017; Jaecks, Bond, \& Quinn, 2016; Thomas, Ganio, Roberts, \& Swearer, 2017), the observation of a similar otolith trace element signature in all juveniles from a given location suggests a common environment and therefore implies recruitment from a single larval pool (Campana, 1999), most likely indicating restricted dispersal from the natal stream. Wide variation in juvenile otolith trace element signatures suggests variation in larval environment and therefore larval recruitment from a diverse range of sources (Gillanders, 2005). Comparison of trace element signatures in juveniles collected from different streams can thus indicate whether larvae developed in one common pool or many (Campana, 1999; Carlson, Fincel, \& Graeb, 2017; Gillanders, 2005; Grammer et al. 2017). However, as water chemistry is influenced by geology, regions with similar geologies may be difficult to distinguish. To allow comparison with genetic structuring, the five tributaries of Wanaka and Wakatipu used in the genetic portion of this study were again selected as sampling sites for otolith trace element analyses. Due to logistic and financial constraints, only five coastal streams grouped into three broader regions (Region one: Breccia Creek, Grave Creek; Region two: Thirteen Mile Creek, Kararoa Creek; Region three: Fox River) were selected from the 16 sites used in the genetics portion of this study. These coastal streams were selected to have similar catchment size to the tributaries selected within Wanaka and Wakatipu, and to span as much of the north-south range as possible (Fig. 1).

\section{Otolith microchemistry techniques and analyses}

To collect fish for otolith analyses, ten juveniles that had recently returned from their pelagic developing habitat to a fluvial environment were collected from each coastal stream and lake tributary via backpack electric fishing (Kainga EFM300; NIWA Instrument Systems), euthanized using an overdose of anesthetic, and preserved in $90 \%$ ethanol. Sagittal otoliths were then retrieved in the laboratory. Otolith surfaces were cleaned by sonication in ultra-pure water for $30 \mathrm{~s}$, allowed to air dry, then mounted on a standard glass microscope slide covered with double sided sticky tape (Warburton, Reid, Stirling, \& Closs, 2017). Larval otolith trace element signatures were obtained by depth profiling laser ablation inductively coupled plasma mass spectrometry (LA-ICP-MS) as described in Warburton et al. (2017). Depth profiling was completed at the University of Otago Centre for Trace Element Analysis on an Agilent 7500cs ICP-MS coupled to a Resonetics (now ASI) 155 RESOlution M-50 laser ablation system powered by a Coherent $193 \mathrm{~nm} \operatorname{ArF}$ excimer laser. During depth profiling, the laser was repeatedly fired at the same spot on the surface of the otolith, 'drilling' through the otolith and obtaining a complete life-history profile from otolith surface (point of capture) through to the core (hatch). Possible down-hole effects associated with depth profiling were minimized following the recommendations of Warburton et al. (2017). A $75 \mu \mathrm{m}$ spot size was used at a firing rate of $10 \mathrm{~Hz}$ tuned to capture an 11-element suite (Ca, Ba, $\mathrm{Sr}, \mathrm{Rb}, \mathrm{Mn}, \mathrm{Li}, \mathrm{Cu}, \mathrm{Ni}, \mathrm{B}, \mathrm{Mg}, \mathrm{Al}$ ) with a sample fluence of $2.5 \pm 0.1 \mathrm{Jcm}^{-2}$. Condensation and contamination were minimized by completing ablations in a chamber containing an atmosphere of pure helium gas. Possible machine drift was accounted for by taking a 20-s gas blank at the start of each ablation, and standards (NIST 610, NIST 612, MACS-3) were run bracketing every 10 samples. Standard values for NIST were obtained from Jochum et al. (2011) and the standard value for MACS-3 was obtained from Chen et al. (2011). The chance of hitting otolith cores was maximized by mounting slides in a sampling cell and using a 400x video microscope to view otoliths.

Data were processed using the Trace_Elements and Trace_Elements_IS data reduction schemes in IOLITE version 2.5 (Paton, Hellstrom, Paul, Woodhead, \& Hergt, 2011), with ${ }^{43} \mathrm{Ca}$ set as the internal standard, resulting in elemental data expressed as a molar ratio of mols element/mols Ca. NIST 610 was set as the calibration standard, while NIST 612 (Jochum et al., 2011) and MACS-3 (Chen et al., 2011) were used as reference materials. To interpret otolith signatures, the otolith core was identified by a spike in Mn (Ruttenberg et al., 2005), and the 7-10 $\mu \mathrm{m}$ of drilling depth before this spike was selected as the larval development period, as indicated by traces (see Supplementary material, Appendix 1, Fig. A1). Elemental concentrations within this period were averaged to use as a standardized, comparable larval development value. Otolith trace element signatures lacking Mn spikes were excluded from further analyses due to the likelihood of having missed the natal core region, and this resulted in final sample sizes of 47 (coastal), 44 
(Wanaka), and 47 (Wakatipu). Marine versus lake development was determined by interpreting patterns in $\mathrm{Ba}$ and Sr. High Sr and low Ba are characteristic of marine development, and the opposite is generally true in freshwater (Campana, 1999; Warburton et al., 2017).

Statistical methods similar to Hogan et al. (2014) were used to determine population structuring. To determine whether a linear discriminant analysis (LDA) could be used for evidence of population structure in otolith signatures, boxplots for each element were used to determine which elements were most likely to show variation. A six-element suite $(\mathrm{Sr}, \mathrm{Ba}, \mathrm{Rb}, \mathrm{Mg}, \mathrm{Cu}, \mathrm{Ni}$ ) was selected based on these box plots and likelihood of element stability in the otolith (see Campana, 1999). An LDA was then run on these six elements in the R statistical environment using the MASS package (R Core Team, 2015; Ripley et al., 2011) to examine clustering of otolith micro-chemical signatures that would indicate discrete larval development pools. To determine the geographic scale on which population structuring occurred, an LDA was first run at the broad-scale system level (i.e. attempting to reclassify individuals only to the three broad-scale habitats of 'Coast', 'Wanaka', and 'Wakatipu'). To determine to what extent, if any, populations are structured within-system, additional LDAs were then run at a finer scale, i.e. within each lake or coastal region by site. See Fig. 1 for sampling sites and a priori regional classification. Re-classification rate was determined using training and test data where half of the samples were used to determine clustering and the other half then used for re-classification.

\section{Larval trawling techniques and analyses (hypothesis 5)}

To aid in interpretation of otolith trace element signatures and infer larval behaviour during their pelagic development, larval trawls were conducted between 9-16 Jan 2016, aligning with the Sep -Nov peak spawning period of landlocked $G$. brevipinnis (McDowall, 1990). This time period ensured that both newly-hatched larvae and older cohorts were present, providing insight into where larvae were located for the duration of their entire pelagic development period. Night time trawls were conducted given that nocturnal migrations of larvae into surface waters commonly occur (Taylor, Graynoth, \& James, 2000). Larval habitat use in the lakes was assessed in three habitats: river plumes, nearshore, and offshore. River plume sites were located near river mouths in the turbid water outflowing from four tributaries from each lake, including the two largest tributaries (Fig. 1; Wakatipu: Rees River, Dart River; Wanaka: Makarora River, Matukituki River) and two smaller tributaries (Wakatipu: Greenstone River, Buckler Burn; Wanaka: Albert Burn, Boundary Creek). Nearshore sites were located $<30 \mathrm{~m}$ from the shoreline and $>100 \mathrm{~m}$ from other tributaries. Offshore sites were $>200 \mathrm{~m}$ from the shore. Sampling was conducted in a hierarchical design where each tributary was sampled as a set of plume, nearshore and offshore sites.

Larvae were sampled using an ichthyoplankton tow net $(125 \times 50 \mathrm{~cm}, 250 \mu \mathrm{m}$ mesh) with a flow meter (Ocean Test Equipment, Inc.; www.oceantestequip.com) mounted in the mouth of the trawl. Tows lasted 4 mins at approximately $4 \mathrm{kmh}^{-1}$. Plumes were often relatively small, so were trawled in a circular motion to remain within them. Trawl contents were immediately placed in $5 \%$ formalin. In the laboratory, larvae were separated from organic and inorganic material, and identified to species. To confirm species identification, a subsample of larvae from each trawl was preserved in $90 \%$ ethanol in the field, and the identity of 10 randomly selected larvae per trawl was genetically confirmed using BLAST searches (Altschul, Gish, Miller, Myers, \& Lipman, 1990) of cytochrome b, amplified following the methods of Waters, Craw, Youngson, and Wallis (2001). Gobiomorphus cotidianus was the only other species likely to be encountered in these lakes, but is morphologically distinct from G. brevipinnis(Jarvis \& Closs, 2015). The density of larvae was determined by dividing total number captured by the volume of water filtered (as determined by the net measurements, flow meter, and trawl time), resulting in a standardized estimate of the number of larvae per $\mathrm{m}^{3}$ of water.

A $G$-test was used to assess differences in larval distribution differences across offshore, near shore and tributary habitats of each tributary. A one-tailed test was employed as larval densities are predicted to be higher in plumes than other sampling locations.

\section{Results}




\section{Genetics}

All loci were highly polymorphic, ranging from 21 alleles at $G b r 12$ to 32 at Gvu 05 . Population mean $H$ 。 ranged from 0.64 to 0.83 (mean 0.76) and $H_{\mathrm{e}}$ from 0.57 to 0.82 (mean 0.75; Table 1). Allelic richness across all loci tended to be lower in lake-developing populations, ranging from 2.8 in Lake Christabel to 4.9 in Lake Wanaka, while coastal populations ranged from 3.9 to 6.3. Departures from Hardy-Weinberg equilibrium were found in 49 out of 240 locus-population combinations before stepwise Bonferroni correction. As 11 of these occurred at $G b r$ 130, and 21 occurred at Gbr 140, these loci were excluded. Bonferroni corrections were then applied with only 1 of 192 remaining out of equilibrium after stepwise Bonferroni corrections $(p$ $<0.0003)$. No locus was affected by null alleles in any sample, so all remaining loci were used in the study.

All landlocked populations exhibited a higher degree of genetic structuring on a lake by lake basis, when compared to diadromous populations (Fig. 2a), regardless of distance from coastal populations (Mantel $p$ $=0.07$; see Supplementary Tables A1, A2 for full results). Landlocked systems had pairwise $F$ sTvalues of approximately 0.03-0.06 when compared to immediate downstream sites less than $5 \mathrm{~km}$ away (Fig. 2a,b). Lakes located in the same catchments (L. Rotoiti, L. Rotoroa), had lower $F$ ST values, resulting in a significant relationship with increasing distance (Mantel $p=0.04$ ). Comparisons among coastal streams tend to have lower $F$ ST values, but significantly increase with geographic distance (Mantel, $p=0.04$ ). High structuring levels were present in these comparisons even when geographic distance was relatively small and sites were located in the same catchment, such as an $F$ ST value of 0.05 for Smokey and Stoney Creeks, $18 \mathrm{~km}$ apart. Structuring within the respective tributaries of L. Wanaka and L. Wakatipu was relatively low, comparable to that of among coastal stream comparisons $\left(F_{\mathrm{ST}}=0.01-0.03\right)$, and no structure was shown by STRUCTURE analysis (Supplementary Fig. A2; Supplementary Table A3).

Patterns present in $F$ ST scores were corroborated by patterns identified using STRUCTURE (Fig. 3). STRUCTURE initially split populations in the tributaries of east coast lakes (Wanaka and Wakatipu) from all sites at $K=2$. At $K=3$, the tributaries of west coast lakes were split from coastal west coast sites. Tributaries of L. Paringa and L. Moeraki split at $K=4$ with tributaries of Lake Cristabel beginning to split at $K=5$. Tributaries of L. Wanaka and L. Wakatipu are clearly split at $K=6$, which was determined as the most likely population number using Evanno's method. At $K=9$ both tributaries of both L. Moeraki and L. Cristabel are clearly split form the other west coast lakes (Fig. 3). Within lake STRUCTURE results did not show distinct population clustering for tributaries of L. Wakatipu or L. Wanaka (Supplementary material, Fig. A2).

\section{Otoliths}

The larval development period of all otoliths from juvenile G. brevipinnis collected from lake tributaries lacked the high Sr:Ca ratios indicative of a diadromous life-history, whereas those from coastal populations all displayed high Sr:Ca and low Ba:Ca. That is, all individuals in lake tributaries had developed in freshwater, while all those caught from coastal streams had developed in the ocean. Linear discriminant analysis suggested that (in order of importance): $\mathrm{Rb}, \mathrm{Ba}, \mathrm{Sr}, \mathrm{Mg}, \mathrm{Cu}, \mathrm{Ni}$ were useful in stock discrimination, with linear discriminant (LD1) explaining $>67 \%$ of variation in all systems (Table 2).

At the largest (system) spatial scale, evidence of population structuring was clear, with coastal, Wanaka, and Wakatipu samples all forming distinct clusters (Fig. 4a), with reclassification to system of capture 96\% successful (Table 2). At a finer scale (the a prioriregions within each lake and along the coast), regional clusters were generally well defined (Fig. 4b), and reclassification success rates were again high: 94\% for coastal regions, $86 \%$ within Wanaka and 71\% within Wakatipu (Table 2). At the finest spatial scale, individual sampling sites still show distinct, though less well-defined, clustering (Fig. 4b), and reclassification success rates for coastal, Wanaka, and Wakatipu sites were $62.5 \%, 78.6 \%$, and $60 \%$ respectively (Table 2). Reclassification success was reflected in the LDA plots, with clear clustering present at high reclassification levels (e.g. Wanaka), and greater overlap occurring with lower reclassification levels (e.g. Wakatipu) (Fig. $3 \mathrm{~b})$.

\section{Trawling}


Trawling in the lakes collected a total of 1,991 larvae, with $95 \%$ being collected in river plumes, $2 \%$ in nearshore areas and 3\% in offshore areas. All large river plumes had significantly higher densities of larvae than trawls collected from offshore or nearshore sites. There were no significant density differences among small river sites, although the highest densities were recorded in the plumes associated with Buckler Burn and Albert Burn (Fig. 5.) Statistical outputs relating to larval trawling are available in Supplementary material (Appendix 1, Table A4).

\section{Discussion}

Our results show various levels of population structuring across a range of spatial and temporal scales. Genetic structuring of lake- and ocean-developing G. brevipinnis populations indicates that lake populations are generally closed and therefore isolated from downstream coastal populations over long timescales. Collectively, lake tributary populations exhibit greater genetic structuring than coastal populations, but comparatively little genetic structuring is evident within individual lakes or along the coast, consistent with more open populations dynamics and within-system exchange of individuals. On shorter timescales, within-system otolith trace element signatures align with genetic results, suggesting that no migration occurs between lake tributary populations and coastal stream populations. Otolith trace element signatures also indicate further structuring on shorter timescales, with a semi-closed meta-population structuring of individual catchments or regions within lake and coastal systems. Larval plume residence is likely a simple consequence of rheotaxis (Hicks, 2012), a behavioural mechanism that may generate population isolation and structuring across both short and long timescales. Due to its 'leaky' nature, plume residence may result in populations being closed across short timescales and driven by self-recruitment, but not sufficient to prevent limited dispersal and genetic exchange among rivers, leading to open population dynamics on a longer timescale.

\section{Long-term population structure}

When compared to coastal stream populations in close proximity, lake tributaries have higher levels of structuring, indicating that each lake creates a closed population subject to genetic drift. In contrast, genetic structuring is relatively homogeneous within each lake and coastal region, indicating that the within-system meta-populations evident via otolith microchemistry results are not as isolated, and therefore relatively open, over longer timescales. Patterns of closed populations in lakes persist even where lakes are in close proximity to, and have open access to, the marine environment. Thus, lakes appear to act as barriers to upstream migration, despite presenting no obvious physical barrier to movement (see Gouskov \& Vorburger, 2016). Mechanisms potentially leading to this isolation are unclear, but could be related to simple behaviours such as preference for current and upstream orientation (Hicks, 2012). By preferring to orient into the current, lake-developing larvae would seem likely to be retained in their natal river plume, as suggested by our larval trawling results, and adults and juveniles from downstream diadromous populations are unlikely to move upstream through a lake due to the absence of directional cues provided by water currents (Concepcion \& Nelson, 1999), thus preventing exchange. Within lake and within-coast comparisons suggest relatively low genetic structuring, implying that catchment level meta-populations are open over long timescales, aligning with other studies on dispersive larvae which find connectivity at broad spatial and temporal scales (McDowall, 2003; McDowall, 2007).

\section{Short-term population structure}

Otolith trace-element signatures show both distinct system level population structuring, aligning with genetic results, and within system meta-population structuring, thus detecting a level of fine-scale relatively closed populations not detected by genetic methods. Distinct otolith trace element signatures formed between lake tributaries and coastal streams are not unexpected in our case due to impermeable hydro-electric dams downstream of lakes Wanaka and Wakatipu, as well as the distances involved. Further, a lack of mixing has previously been found in Lakes Moeraki and Paringa, which both have unimpeded access to the coast (Hicks et al., 2017), suggesting that connectivity is even more unlikely when a physical barrier is present. However, distinct trace element signatures between Lakes Wanaka and Wakatipu suggests retention within each lake, and therefore a closed population, despite the absence of any impermeable physical barriers that would 
prevent movement between the two. These closed populations must persist long term, as the same pattern can be seen in the genetic results. In contrast, both marine and freshwater populations seen in our study also formed otolith trace element clusters when grouped by tributary or region, indicating fine scale, catchmentlevel, semi-closed population structuring within coast or lake, similar to other studies (Hogan et al., 2014; Smith \& Kwak, 2014; Warburton et al., 2018). Even the less distinct clusters (e.g. in L. Wakatipu) still had much higher reclassification success than would be expected if recruitment was largely from unstructured pools (e.g. Hickford \& Schiel, 2016), suggesting at least some degree of larval philopatry (Warburton et al., 2018). While genetic population structuring could occur through mechanisms such as reproductive isolation via altered spawning time, we observed catchment and lake level structuring in the otolith trace element signatures of a single cohort. These results suggest behavioural mechanisms are restricting widespread larval dispersal from their natal streams, which would also result in retention within lakes.

\section{Larval behaviour as a mechanism for population structuring}

Larval plume residence found in this study suggests a behavioural mechanism that isolates populations within different streams or regions, and leads to long term isolation of lake populations. Nearly all larvae found in the study were present in river plumes, suggesting substantial retention within each stream draining into a lake or the sea. This process should result in the formation of semi-closed meta-population within lakes and along coastlines, concordant with the patterns seen in otolith trace element signatures. Further, plume residence seemingly provides a mechanism by which larvae avoid drifting out of lakes (David et al., 2019; Hicks, 2012), isolating populations within lakes, even when close to the coast. The actual behaviour maintaining larvae within plumes is unclear, although the observation of strong rheotaxis even in newly hatched larvae (Hicks, 2012), could provide a simple explanation for the retention of larvae in river plumes. Similarly, the river plumes entering lakes studied here anecdotally appeared to have more zooplankton than other sites, suggesting food availability may also favour retention in these systems. River plumes represent dynamic environments and thus the degree of retention is likely to vary both spatially between river plumes, and temporally in response to changes in flow. Similarly rare dispersal events mediated by environmental conditions have been identified in other systems such as arid floodplains (e.g. Mossop et al., 2015), resulting in relatively low genetic structuring despite largely disconnected ecological populations. Whilst the majority of larvae collected were in river plumes, the collection of small numbers of larvae in offshore habitats suggests leakage from river plumes, likely providing a degree of population connectivity within lake and marine pelagic habitats, thus maintaining population and hence genetic connectivity resulting in open population signatures over longer timescales.

\section{Evolutionary implications}

Behaviours that retain larvae within river plumes and resist dispersal provide a simple mechanism that could interact with landscape to produce context dependent patterns of population connectivity and isolation. Collectively, our results form a case study describing how behaviour might interact with geologic events (Craw et al., 2016) and landscape to facilitate divergence of landlocked populations of an ancestral G. brevipinnis, that may have led to the subsequent radiation of the non-migratory G. vulgaris species-complex (Allibone \& Wallis, 1993; Allibone et al., 1996; Burridge, McDowall, Craw, Wilson, \& Waters, 2012; Waters et al., 2010). Our results confirm that lake-developing populations of $G$. brevipinnis are isolated and genetically divergent, despite the relative proximity and potential connectivity with other lake populations and even diadromous populations in some cases. Similar speciation patterns are repeatedly seen in other amphidromous fish which universally have a pelagic larval phase but isolated adult populations (Augspurger, et al., 2017), including members of the Cottidae (Dennenmoser, Rogers, \& Vamosi, 2014; Goto et al., 2015), Eleotridae (Nordlie, 2012) and Gobiidae (Keith \& Lord, 2011), which are likely influenced by similar interactions between landscape, geology and behaviour.

Our results also have implications for the management and conservation of amphidromous species, particularly those in which non-diadromous populations are readily formed. Our otolith microchemical results, indicating that short-term population-sustaining processes may occur at the scale of individual catchments or isolated geographical regions, add further weight to the notion that management may have to be un- 
dertaken at the local (Hicks et al. 2017; Warburton et al., 2018) rather than island or distribution wide (Cook, Bernays, Pringle, \& Hughes, 2009) scale. Further, the translocation of individuals from landlocked populations of facultatively amphidromous species has been suggested as a potential management strategy to enhance typically more degraded, lowland diadromous populations (e.g. David, 2003). Our finding of high genetic differentiation in landlocked populations, together with previously identified ecological differences between landlocked and diadromous populations (Augspurger \& Closs, 2019), suggest that such a strategy should be approached with caution. Indeed, the translocation of a facultatively amphidromous shrimp before high levels of cryptic diversity were recognized has been recognized as resulting in the rapid extinction of the local genotype (Cook et al. 2006; Hughes et al. 2003).

\section{Acknowledgements}

We thank Tony Stumbo and Kim Garrett for assistance in the field, Malcolm Reid for advice and assistance with LA-ICP-MS, Ken Miller for assistance preparing maps, Ryan Easton for assisting with document preparation, and various landowners for sampling site access. All sampling was conducted in accordance with local laws and regulations, and with approval from the University of Otago Animal Ethics Committee. This work was funded by the Department of Zoology, University of Otago, Dunedin, New Zealand. During the study, JMA was supported by a University of Otago Doctoral Scholarship.

\section{References}

Allibone, R. M., \& Wallis, G. P. (1993). Genetic variation and diadromy in some native New Zealand galaxiids (Teleostei: Galaxiidae).Biological Journal of the Linnean Society , 50 , 19-33.

Allibone, R. M., Crowl, T. A., Holmes, J. M., King, T. M., McDowall, R. M., Townsend, C. R., \& Wallis, G. P. (1996). Isozyme analysis of Galaxias species (Teleostei: Galaxiidae) from the Taieri River, South Island, New Zealand: A species complex revealed. Biological Journal of the Linnean Society , 57 , 107-127.

Altschul, S. F., Gish, W., Miller, W., Myers, E. W., \& Lipman, D. J. (1990). Basic local alignment search tool. Journal of Molecular Biology, 215 , 403-410.

Augspurger, J. M., Warburton, M. L., \& Closs, G. P. (2017). Life-history plasticity in amphidromous and catadromous fishes: A continuum of strategies. Reviews in Fish Biology and Fisheries ,27, 177-192.

Augspurger, J. M., \& Closs, G. P. (2019). Early life-history adaptation influences conservation approaches for facultatively amphidromous fish.Aquatic Conservation: Marine and Freshwater Ecosystems . doi: 10.1002/aqc.3077

Booth, W., Montgomery, W. I., \& Prodöhl, P. A. (2009). Spatial genetic structuring in a vagile species, the European wood mouse. Journal of Zoology , 279 , 219-228.

Burridge, C. P., McDowall, R. M., Craw, D., Wilson, M. V. H., \& Waters, J. M. (2012). Marine dispersal as a pre-requisite for Gondwanan vicariance among elements of the galaxiid fish fauna. Journal of Biogeography , $39,306-321$.

Campana, S. E. (1999). Chemistry and composition of fish otoliths: Pathways, mechanisms and applications. Marine Ecology Progress Series , 188 , 263-297.

Carlson, A. K, Fincel, M. J., \& Graeb, B. D. S. (2017). Otolith chemistry indicates walleye movement and entrainment in a large serial reservoir system. Fisheries Management and Ecology , 24, 217-229.

Carroll, S.P., Hendry, A. P., Reznick, D. N., \& Fox, C. W. (2007). Evolution on ecological time-scales. Functional Ecology,21, 387-393.

Casquet, J., Thebaud, C., \& Gillespie, R. G. (2012). Chelex without boiling, a rapid and easy technique to obtain stable amplifiable DNA from small amounts of ethanol-stored spiders. Molecular Ecology Resources , 12, 136-141. 
Chen, L., Liu, Y., Hu, Z., Gao, S., Zong, K., \& Chen, H. (2011). Accurate determinations of fifty-four major and trace elements in carbonate by LA-ICP-MS using normalization strategy of bulk components as $100 \%$. Chemical Geology , 284, 283-295.

Concepcion, G. B., \& Nelson, S. G. (1999). Effects of a dam and reservoir on the distributions and densities of macrofauna in tropical streams of Guam (Mariana Islands). Journal of Freshwater Ecology ,14, 447-454.

Cook, B. D., Baker, A. M., Page, T. J., Grant, S. C., Fawcett, J.H., Hurwood, D. A., \& Hughes, J. M. (2006). Biogeographic history of an Australian freshwater shrimp, Paratya australiensis (Atyidae): The role life history transition in phylogeographic diversification.Molecular Ecology , 15 , 1083-1093.

Cook, B. D., Bernays, S., Pringle, C. M., \& Hughes, J. M. (2009). Marine dispersal determines the genetic population structure of migratory stream fauna of Puerto Rico: Evidence for island-scale population recovery processes. Journal of the North American Benthological Society , 28, 709-718.

Cowen, R. K., Lwiza, K. M. M., Sponaugle, S., Paris, C. B., \& Olson, D. B. (2000). Connectivity of marine populations: Open or closed?Science, 287, 857-859.

Craw, D., Upton, P., Burridge, C. P., Wallis, G. P., \& Waters, J. M. (2016). Rapid biological speciation driven by tectonic evolution in New Zealand. Nature Geoscience , 9 , 140-144.

David, B. O. (2003). Conservation, management and research directions for giant kokopu (Galaxias argenteus) in Otago (DOC Science Internal Series 112). Wellington, New Zealand: New Zealand Department of Conservation.

David, B. O., Jarvis, M., Ozkundakci, D., Collier, K. J., Hicks, A. S., \& Reid, M. (2019). To sea or not to sea? Multiple lines of evidence reveal the contribution of non-diadromous recruitment for supporting endemic fish populations within New Zealand's longest river.Aquatic Conservation: Marine and Freshwater Ecosystems, 29,1409-1423

Dennenmoser, S., Rogers, S. M., \& Vamosi, S. M. (2014). Genetic population structure in prickly sculpin (Cottus asper ) reflects isolation-by-environment between two life-history ecotypes.Biological Journal of the Linnean Society , 113 ,943-957.

Dingle, H., \& Drake, V. A. (2007). What is migration?BioScience, 57 , 113-121.

Dunning, J. B., Danielson, B. J., \& Pulliam, H.R. (1992). Ecological processes that affect populations in complex landscapes. Oikos ,65, 169-175.

Elsdon, T. S., \& Gillanders, B. M. (2005). Consistency of patterns between laboratory experiments and field collected fish in otolith chemistry: An example and applications for salinity reconstructions. Marine and Freshwater Research , 56 , 609-617.

Fussmann, G. F., Loreau, M., \& Abrams, P. A. (2007). Eco-evolutionary dynamics of communities and ecosystems. Functional Ecology ,21, 465-477.

Gillanders, B. M. (2005). Otolith chemistry to determine movements of diadromous and freshwater fish. Aquatic Living Resources ,18 , 291-300.

Goto, A., \& Arai, T. (2003). Migratory histories of three types of Cottus pollux (small-egg, middle-egg, and large-egg types) as revealed by otolith microchemistry. Ichthyological Research,50 , 67-72.

Goto, A., Yokoyama, R., \& Sideleva, V. G. (2015). Evolutionary diversification in freshwater sculpins (Cottoidea): A review of two major adaptive radiations. Environmental Biology of Fishes ,98 , 307-335.

Gouskov, A., \& Vorburger, C. (2016). River fragmentation and fish population structure: A comparison of three Swiss midland rivers.Freshwater Science, 35, 689-700. 
Grammer, G. L., Morrongiello, J. R., Izzo, C., Hawthorne, P. J., Middleton, J. F., \& Gillanders, B. M. (2017). Coupling biogeochemical tracers with fish growth reveals physiological and environmental controls on otolith chemistry. Ecological Monographs , 87 , 487-507.

Gruber, B., \& Adamack, A. T. (2015). Landgenreport: A new r function to simplify landscape genetic analysis using resistance surface layers. Molecular Ecology Resources , 15, 1172-1178.

Hickford, M. J. H., \& Schiel, D. R. (2016). Otolith microchemistry of the amphidromous Galaxias maculatus shows recruitment to coastal rivers from unstructured larval pools. Marine Ecology Progress Series , 548 , $197-207$.

Hicks, A. S. (2012). Facultative amphidromy in galaxiids and bullies: The science, ecology, and management implications (Unpublished PhD thesis). University of Otago.

Hicks, A. S., Jarvis, M. G., David, B. O., Waters, J. M., Norman, M. D., \& Closs, G. P. (2017). Lake and species specific patterns of non-diadromous recruitment in amphidromous fish: The importance of local recruitment and habitat requirements. Marine and Freshwater Research , 68 , 2315-2323.

Hogan, J. D., Blum, M. J., Gilliam, J. F., Bickford, N., \& McIntyre, P. B. (2014). Consequences of alternative dispersal strategies in a putatively amphidromous fish. Ecology , 95, 2397-2408.

Hughes, J. M., Goudkamp, K., Hurwood, D., Hancock, M., \& Bunn, S. (2003). Translocation causes extinction of a local population of the freshwater shrimp Paratya australiensis . Conservation Biology , 17 , 1007-1012.

Hughes, J. M., Schmidt, D. J., Macdonald, J. I., Huey, J. A., \& Crook, D. A. (2014). Low interbasin connectivity in a facultatively diadromous fish: Evidence from genetics and otolith chemistry. Molecular Ecology , 23 , 1000-1013.

Jaecks, T., Bond, M. H., \& Quinn, T. P. (2016). Can dietary reliance on Pacific salmon eggs create otolith $\mathrm{Sr} / \mathrm{Ca}$ signatures that mimic anadromy in resident salmonids? Environmental Biology of Fishes ,99 , 237247.

Jarvis, M. G., \& Closs, G. P. (2015). Larval drift of amphidromous Gobiomorphus spp. in a New Zealand coastal stream: A critical spatial and temporal window for protection. New Zealand Journal of Marine and Freshwater Research, 49 , 439-447.

Jarvis, M. G., \& Closs, G. P. (2019). Water infrastructure and the migrations of amphidromous species: Impacts and research requirements. Journal of Ecohydraulics , 4 , 4-13.

Jochum, K. P., Weis, U., Stoll, B., Kuzmin, D., Yang, Q., Raczek, I., .. Enzweiler, J. (2011). Determination of reference values for NIST SRM 610-617 glasses following ISO guidelines. Geostandards and Geoanalytical Research , 35, 397-429.

Jones, G. P., Almany, G. R., Russ, G. R., Sale, P. F., Steneck, R. S., Van Oppen, M. J. H., \& Willis, B. L. (2009). Larval retention and connectivity among populations of corals and reef fishes: History, advances and challenges. Coral Reefs 28, 307-325.

Kamvar, Z. N., Tabima, J. F., \& Grunwald, N. J. (2014). Poppr: An R package for genetic analysis of populations with clonal, partially clonal, and/or sexual reproduction. PeerJ , 2, e281.

Keith, P., \& Lord, C. (2011). Tropical freshwater gobies: Amphidromy as a life cycle. In Patzner, R. A., Van Tassell, J. L., Kovacic, M., \& Kapoor, B. G. (Eds.), The biology of gobies . (pp. 243-277). Boca Raton, FL: CRC Press.

Kekkonen, J., Seppa, P., Jensen, H., Vaisanen, R. A., \& Brommer, J. E. (2011). Low genetic differentiation in a sedentary bird: House sparrow population genetics in a contiguous landscape. Heredity ,106 , 183-190. 
King, K. J., Young, K. D., Waters, J. M., \& Wallis, G. P. (2003). Preliminary genetic analysis of koaro (Galaxias brevipinnis ) in New Zealand lakes: Evidence for allopatric differentiation among lakes but little population subdivision within lakes. Journal of the Royal Society of New Zealand, 33 , 591-600.

Kopelman, N. M., Mayzel, J., Jakobsson, M., Rosenberg, N. A., \& Mayrose, I. (2015). Clumpak: A program for identifying clustering modes and packaging population structure inferences across K. Molecular Ecology Resources , 15 (5), 1179-1191.

Levin, S. A. (1992). The problem of pattern and scale in ecology.Ecology , 73 , 1943-1967.

McDowall, R. M. (1990). New Zealand freshwater fishes: A natural history and guide. Auckland, New Zealand: Heinemann-Reed.

McDowall, R. M. (2003). Hawaiian biogeography and the islands' freshwater fish fauna. Journal of Biogeography ,30 , 703-710.

McDowall, R. M. (2007). On amphidromy, a distinct form of diadromy in aquatic organisms. Fish and Fisheries, 8 , 1-13.

Moody, K. N., Hunter, S. N., Childress, M. J., Blob, R. W., Schoenfuss, H. L., Blum, M. J., \& Ptacek, M. B. (2015). Local adaptation despite high gene flow in the waterfall-climbing Hawaiian goby,Sicyopterus stimpsoni. Molecular Ecology , 24, 545-563.

Mossop, K. D., Adams, M., Unmack, P. J., Smith Date, K. L., Wong, B. B. M., \& Chapple, D. G. (2015). Dispersal in the desert: ephemeral water drives connectivity and phylogeography of an arid-adapted fish. Journal of Biogeography , 42 , 2374-2388.

Nordlie, F. G. (2012). Life-history characteristics of eleotrid fishes of the western hemisphere, and perils of life in a vanishing environment. Reviews in Fish Biology and Fisheries , 22 , 189-224.

Paton, C., Hellstrom, J., Paul, B., Woodhead, J, \& Hergt, J. (2011). Iolite: Freeware for the visualisation and processing of mass spectrometric data. Journal of Analyical Atomic Spectrometry ,26 , 2508-2518.

Peakall, R., \& Smouse, P. E. (2006). Genalex 6: Genetic analysis in Excel. Population genetic software for teaching and research.Molecular Ecology Notes , 6 , 288-295.

Pinsky, M. L., Saenz-Agudelo, P., Salles, O. C., Almany, G. R., Bode, M., Berumen, M. L., ... Planes, S. (2017). Marine dispersal scales are congruent over evolutionary and ecological time. Current Biology , 27 , $149-154$.

Pritchard, J.K., Stephens, M., \& Donnelly, P. (2000). Inference of population structure using multilocus genotype data. Genetics ,155, 945-959.

R Core Team. (2015). R: A language and environment for statistical computing. R Foundation for Statistical Computing. Vienna, Austria.

Raymond, M., \& Rousset, F. (1995). GENEPOP (version 1.2): Population genetics software for exact tests and ecumenicism. Journal of Heredity , 86, 248-249.

Ripley, B., Bates, D., Hornik, K., Gebhardt, A., \& Firth, D. (2011). Package 'MASS'. Available at: cran.rproject.org/web/packages/MASS.

Rousset, F. (2008). Genepop'007: A complete reimplementation of the Genepop software for Windows and Linux. Molecular Ecology Resources, 8 , 103-106.

Ruttenberg, B. I., Hamilton, S, L., Hickford, M. J. H., Paradis, G. L., Sheehy, M. S., Standish, J. D., ... Warner, R. R. (2005). Elevated levels of trace elements in cores of otoliths and their potential for use as natural tags. Marine Ecology Progress Series , 297 , 273-281. 
Schuelke, M. (2000). An economic method for the fluorescent labeling of PCR fragments. Nature Biotechnology, $18,233-234$.

Sham, P. C., \& Purcell, S. M. (2014). Statistical power and significance testing in large-scale genetic studies. Nature Reviews Genetics , 15 , 335-346.

Slobodkin, L. B. (1980). Growth and regulation of animal populations (2nd ed.) New York, NY: Dover Publications.

Smith, W. E., \& Kwak, T. J. (2014). Otolith microchemistry of tropical diadromous fishes: Spatial and migratory dynamics. Journal of Fish Biology , 84 , 913-928.

Sorensen, P. W., \& Hobson, K. A. (2005). Stable isotope analysis of amphidromous Hawaiian gobies suggests their larvae spend a substantial period of time in freshwater river plumes. Environmental Biology of Fishes , 74, 31-42.

Taylor, M. J., Graynoth, E., \& James, G. D. (2000). Abundance and daytime vertical distribution of planktonic fish larvae in an oligotrophic South Island lake. Hydrobiologia , 421 , 41-46.

Thomas, O. R., Ganio, K., Roberts, B. R., \& Swearer, S. R. (2017). Trace element-protein interactions in endolymph from the inner ear of fish: Implications for environmental reconstructions using fish otolith chemistry. Metallomics, 9 , 239-249.

Townsend, S. M., King, T. M., \& Jamieson, I. G. (2012). Isolation and characterisation of microsatellite markers from the South Island robin (Petroica australis ). Conservation Genetics Resources ,4 , 633-636.

Warburton, M. L., Jarvis, M. G., \& Closs, G. P. (2018). Otolith microchemistry indicates regional philopatry in the larval phase of an amphidromous fish (Gobiomorphus hubbsi). New Zealand Journal of Marine and Freshwater Research, 52, 398-408.

Warburton, M. L., Reid, M. R., Stirling, C. H., \& Closs, G. P. (2017). Validation of depth-profiling LAICP-MS in otolith applications. Canadian Journal of Fisheries and Aquatic Sciences, 74, 572-581.

Waters, J. M., Craw, D., Youngson, J. H., \& Wallis, G. P. (2001). Genes meet geology: Fish phylogeographic pattern reflects ancient, rather than modern, drainage connections. Evolution , 55 , 1844-1851.

Waters, J. M., Esa, Y. B., \& Wallis, G. P. (1999). Characterization of microsatellite loci from a New Zealand freshwater fish (Galaxias vulgaris ) and their potential for analysis of hybridization in Galaxiidae. Molecular Ecology , 8, 1080-1082.

Waters, J. M., Allibone, R. M., \& Wallis, G. P. (2006). Geological subsidence, river capture, and cladogenesis of galaxiid fish lineages in central New Zealand. Biological Journal of the Linnean Society ,88, 367-376.

Waters, J. M., Rowe, D. L., Burridge, C. P., \& Wallis, G. P. (2010). Gene trees versus species trees: Reassessing life-history evolution in a freshwater fish radiation. Systematic Biology , 59 , 504-517.

Yamasaki, Y. Y., Nishida, M., Suzuki, T., Mukai, T., \& Watanabe, K. (2015). Phylogeny, hybridization, and life history evolution ofRhinogobius gobies in Japan, inferred from multiple nuclear gene sequences. Molecular Phylogenetics and Evolution, 90, 20-33.

\section{Data Accessibility}

Primer sets developed are available in Genbank (Accession \#MK783109-MK783118). Raw data and scripts used in the analyses presented are accessible on Dryad at doi:xx.xxxx/dryad.xxxxx.

\section{Author Contributions}

JMA, GPC and TI conceived the initial project. JMA, MGJ, and ASH conducted fieldwork. JMA and MGJ conducted otolith analyses. JMA, TMK, and GPW conducted and interpreted genetic analyses. JMA and MGJ drafted the initial manuscript, and all authors contributed to revisions and approved the 
Table 1: Basic genetic descriptive statistics including mean heterozygosity $\left(H_{\mathrm{o}}\right)$, expected heterozygosity $\left(H_{\mathrm{e}}\right)$, inbreeding coefficient $\left(F_{\text {IS }}\right)$, and mean number of effective alleles. When lakes are present, sites are grouped by catchment, including both landlocked (lake tributary) and coastal (diadromous) populations. The Coastal Stream category is represented by "CS".

\begin{tabular}{lllllll}
\hline Catchment & Site Name & Sample Size & Mean $\boldsymbol{H}_{\mathbf{o}}$ & Mean $\boldsymbol{H}_{\mathbf{e}}$ & $F \mathbf{I S}$ (of mean values) & $N_{\mathbf{e}}$ \\
\hline Wakatipu (landlocked) & L. Wakatipu & 102 & 0.76 & 0.76 & 0.00 & 4.88 \\
Wanaka (landlocked) & L. Wanaka & 87 & 0.78 & 0.78 & 0.01 & 4.92 \\
Buller R. (landlocked) & L. Matiri & 15 & 0.66 & 0.62 & -0.06 & 2.82 \\
Buller R. (landlocked) & L. Rotoroa & 23 & 0.69 & 0.63 & -0.08 & 2.99 \\
Buller R. (landlocked) & L. Rotoiti & 20 & 0.7 & 0.68 & -0.02 & 3.78 \\
Buller R. (diadromous) & Batty Ck & 14 & 0.77 & 0.77 & 0.00 & 4.86 \\
Buller R. (diadromous) & Nine Mile Ck & 7 & 0.81 & 0.8 & -0.01 & 5.34 \\
Buller R. (diadromous) & Ten Mile Ck & 11 & 0.83 & 0.71 & -0.14 & 3.9 \\
Grey R. (landlocked) & Lake Christabel & 15 & 0.64 & 0.57 & -0.11 & 2.76 \\
Grey R. (CS) & Smoke-ho Ck & 20 & 0.70 & 0.74 & 0.05 & 4.08 \\
Grey R. (CS) & Stony Ck & 20 & 0.81 & 0.78 & -0.02 & 3.80 \\
Paringa R. (landlocked) & Panel Ck & 15 & 0.68 & 0.67 & -0.01 & 5.3 \\
Paringa R. (CS) & Potters Ck & 22 & 0.80 & 0.79 & 0.00 & 4.07 \\
Moeraki R. (landlocked) & Mimi Ck & 15 & 0.75 & 0.74 & -0.01 & 6.19 \\
Moeraki R. (CS) & Venture Ck & 20 & 0.80 & 0.80 & -0.01 & 5.72 \\
Moeraki River (CS) & Monroe's Ck & 17 & 0.82 & 0.81 & -0.01 & 5.81 \\
Mahitahi (CS) & Flagstaff Ck & 21 & 0.72 & 0.79 & 0.10 & 6.34 \\
Near Cascade R. (CS) & Smoothwater R. & 23 & 0.73 & 0.81 & 0.11 & 5.8 \\
Cascade R. (CS) & Martyr Tributary & 20 & 0.83 & 0.80 & -0.03 & 4.19 \\
Northern Coast (CS) & Fox R. & 7 & 0.83 & 0.80 & -0.07 & 4.72 \\
Northern Coast (CS) & Kararoa Ck & 7 & 0.76 & 0.77 & 0.02 & 6.02 \\
Northern Coast (CS) & Thirteen Mile Ck & 31 & 0.79 & 0.82 & 0.03 & 6.20 \\
Southern Coast (CS) & Breccia Ck & 34 & 0.83 & 0.81 & -0.02 & 5.28 \\
Southern Coast (CS) & Grave Ck & 31 & 0.81 & 0.79 & -0.02 & 4.75 \\
Overall & & 597 & 0.76 & 0.75 & -0.0 &
\end{tabular}

Table 2: Reclassification rates of linear discriminant analyses (LDA) and linear discriminant (LD1, LD2) percentage variance explained, and corresponding Eigenvalues, classed by system (Coastal, Wanaka, Wakatipu) and within-system region. Classification levels represent a separate LDA run on the level listed system and level listed therein.

\begin{tabular}{lllllll}
\hline System & $\begin{array}{l}\text { Classification } \\
\text { level }\end{array}$ & LD1 & Eigen-value 1 & LD2 & Eigen-value 2 & $\begin{array}{l}\text { Reclassification } \\
\text { rate }\end{array}$ \\
\hline System & System & 0.97 & 0.95 & 0.03 & 0.58 & 96.1 \\
Coastal & Site & 0.98 & 0.97 & 0.01 & 0.29 & 62.5 \\
Wanaka & Site & 0.97 & 0.95 & 0.03 & 0.63 & 78.6 \\
Wakatipu & Site & 0.67 & 0.65 & 0.27 & 0.29 & 60 \\
Coastal & Region & 0.98 & 0.95 & 0.0008 & 0.23 & 93.8 \\
Wanaka & Region & 0.87 & 0.93 & 0.11 & 0.62 & 85.7 \\
Wakatipu & Region & 0.86 & 0.65 & 0.14 & 0.20 & 70.6 \\
\hline
\end{tabular}




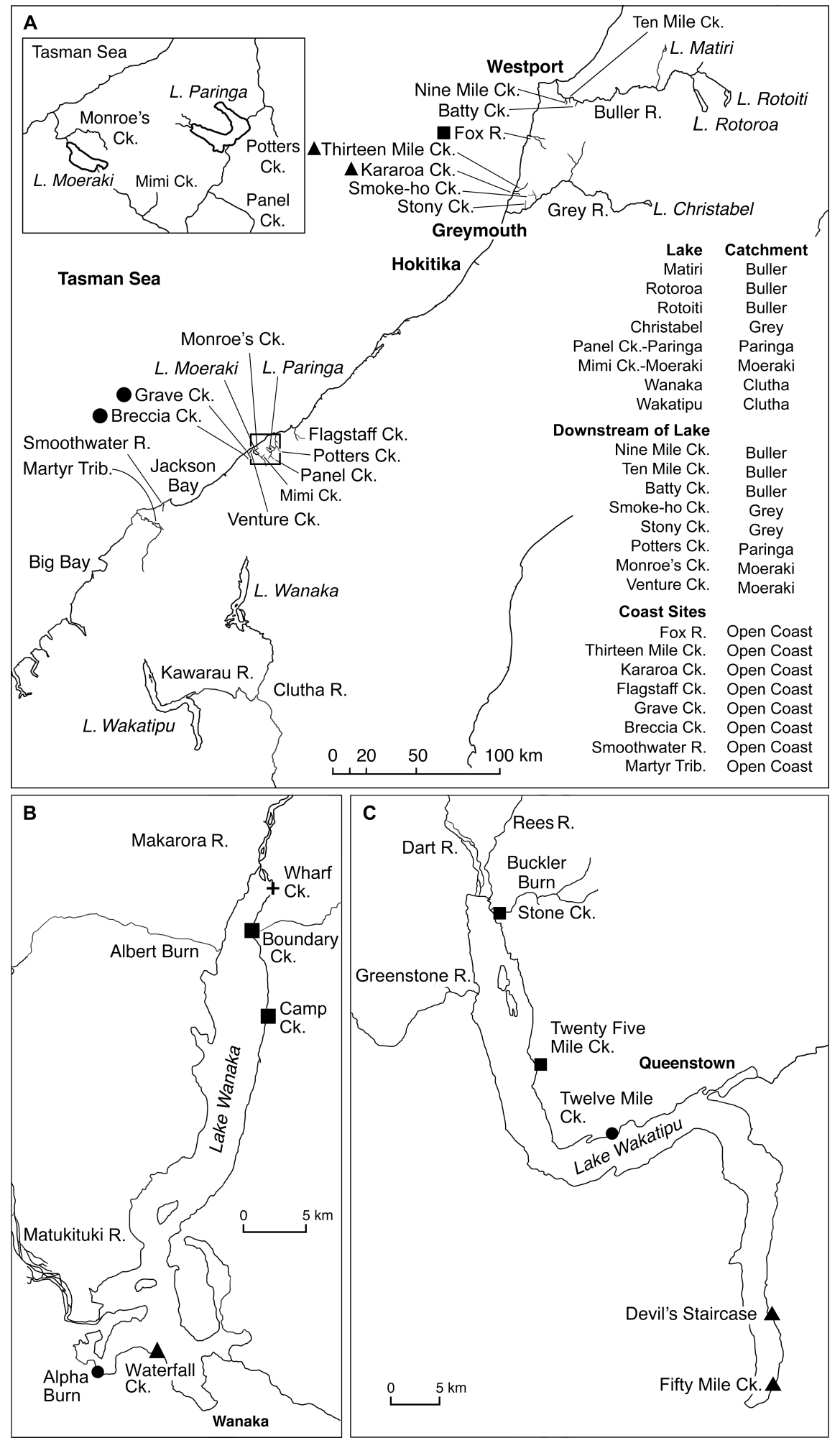




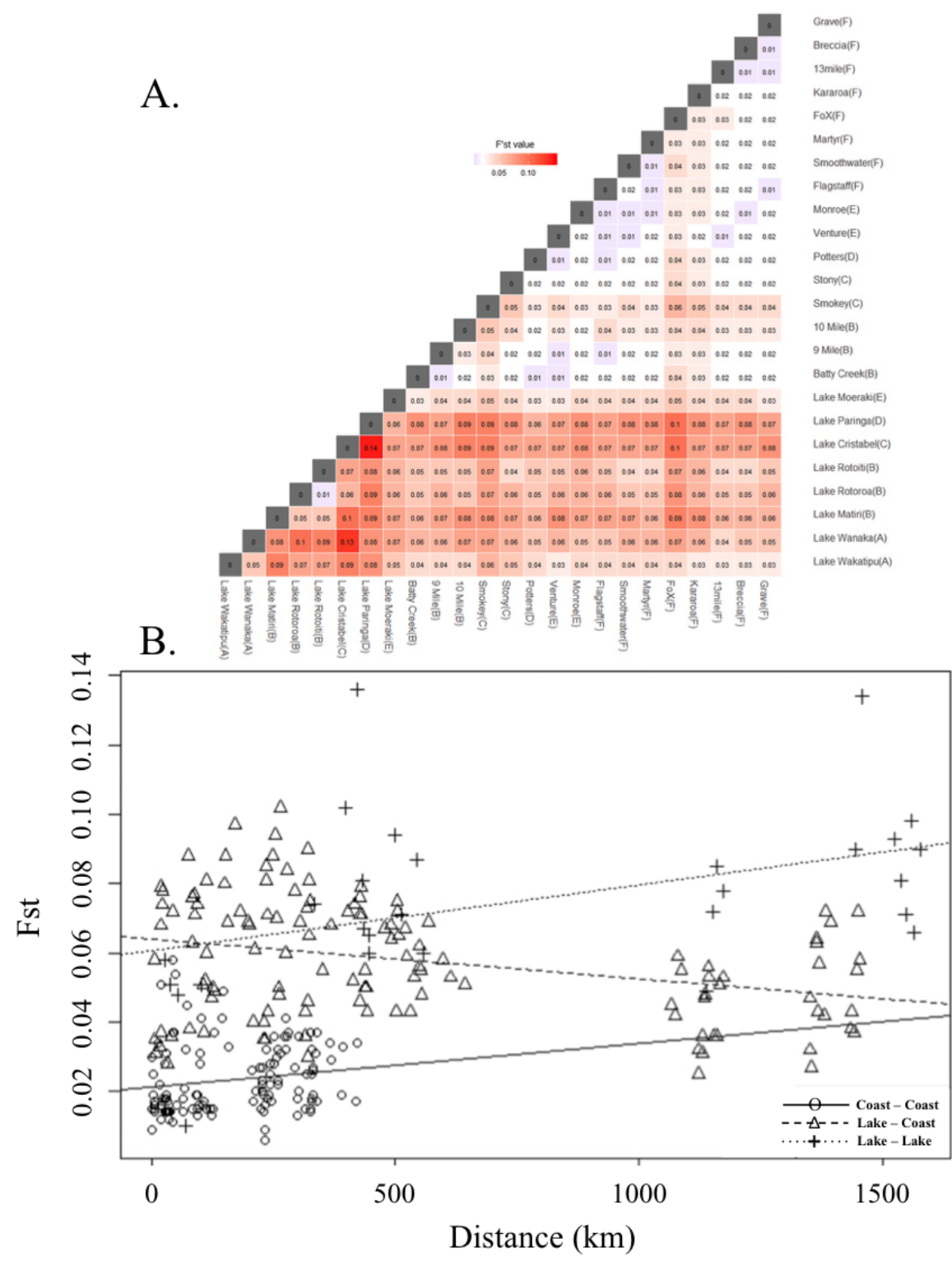




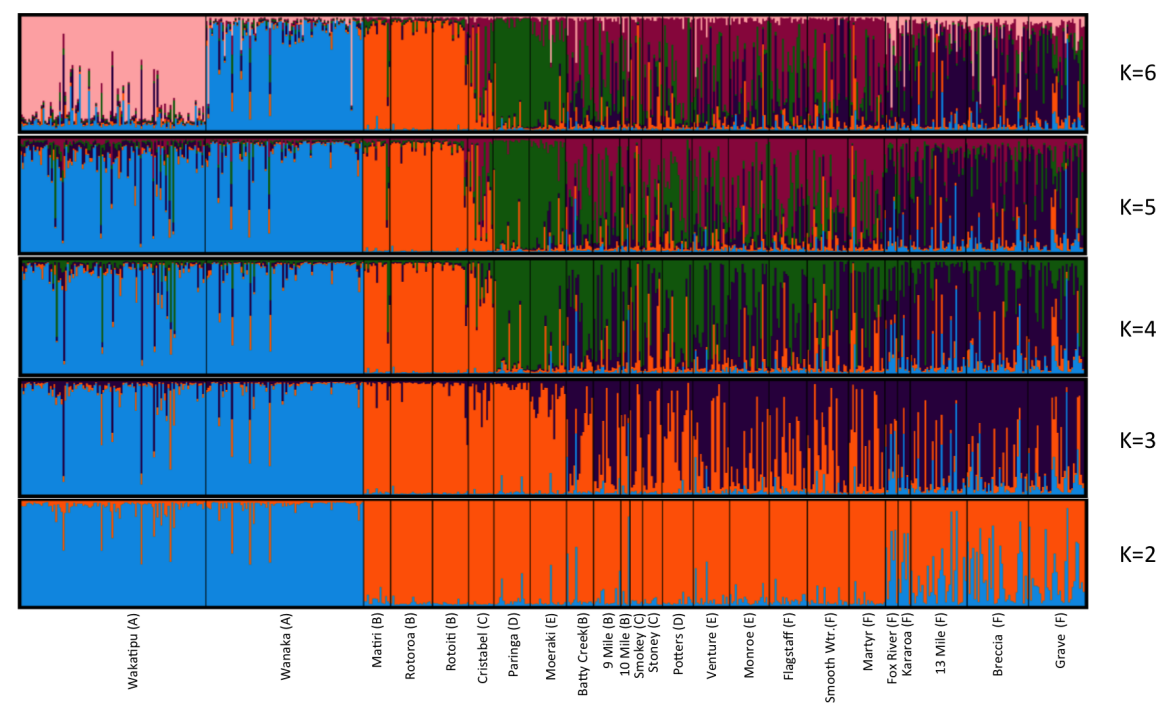




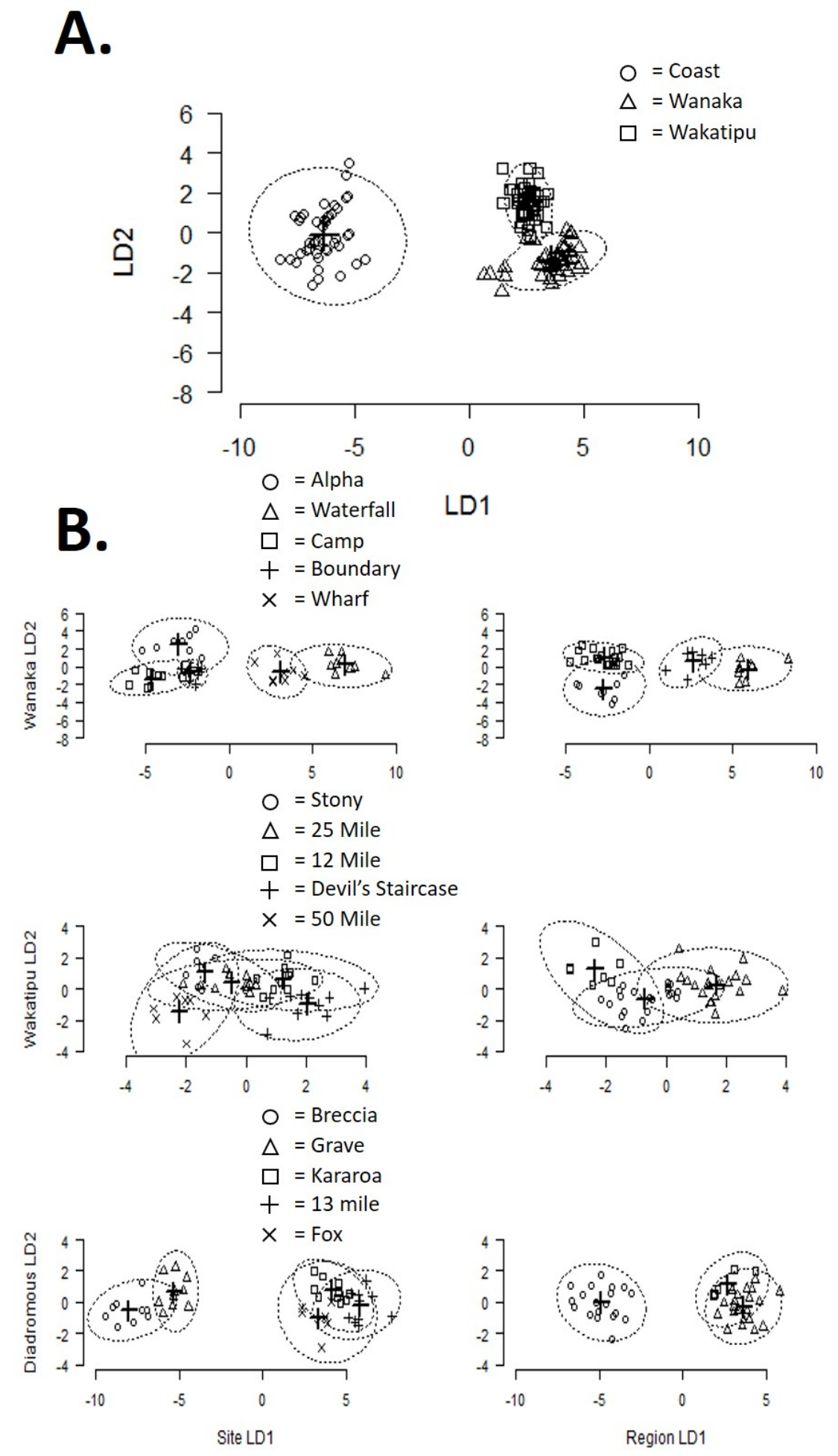




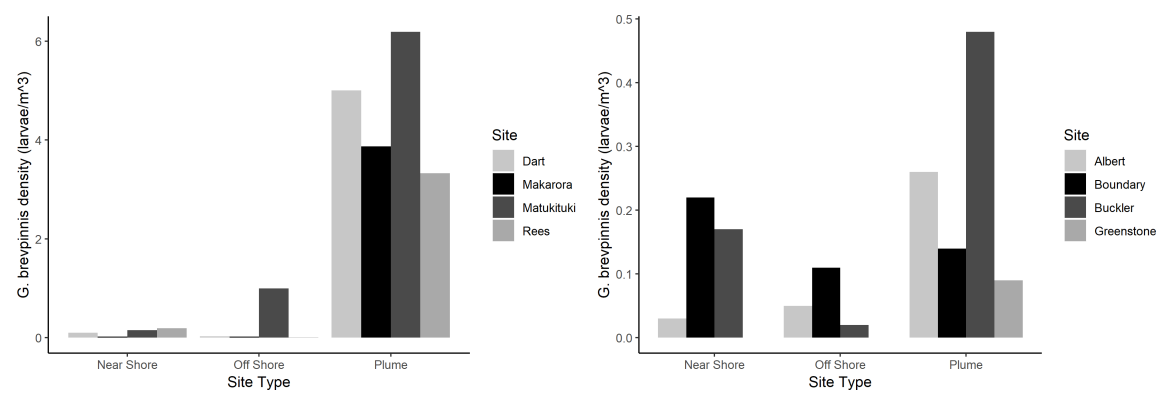

